\title{
An Analysis of the Work of the Information Desk at the University of Illinois Library
}

Miss Erlandson, a reference assistant at the University of Illinois Library, has compressed into this article the results of a master's thesis prepared at the University of Illinois Library School* and approved there in 1943.

$\mathrm{I}^{\mathrm{x}}$ NFORMATION SERVICE of the type described in this study is provided in all libraries. However, only the larger institutions have found it feasible to establish separate desks for this purpose. Since these information desks usually have as their primary purpose the interpretation of the public card catalog, they are frequently referred to as public catalog desks. The information desk at the University of Illinois Library might be so designated if it were not felt that the designation "information desk" appeals to readers with a wider range of questions than does the more restricted title.

The present description and analysis of the information desk at the University of Illinois Library attempts to answer the following questions: (I) What is the character of the information requested at the desk? (2) Judged by the work of the desk, what should be the qualifications of library assistants assigned to it?

\footnotetext{
* Based on a thesis presented in partial fulfillment of requirements for the degree of Master of Arts in Library Science at the University of Illinois. Used with permission of the dean of the graduate school.
}

Based on volume of use of the desk, during what seasons of the year, days of the week, or parts of the day is it most essential to provide information service? (4) What are the implications of this study for the compiling of library manuals for students? The first, second, and fourth questions will be answered with information obtained from the classifying of questions recorded at the desk; the third question must obviously be answered by a statistical analysis of the number of questions recorded during various time periods.

The information desk is not the only information agency in the University of Illinois Library system. Questions answered at this desk are also asked at all other public service desks and they are of course addressed also to individuals working at the card catalog. This study, therefore, does not purport to analyze all the information service furnished by the university library but rather to describe what is done at this particular point.

The data used as a basis for this study were: records of all questions asked at the desk during its first three years of service, statistics kept by the desk, and annual reports of the reference department. Observations from personal experience over a period of four years were of help in interpreting the data. The classification scheme for questions was prepared especially for 
this study, since no earlier system of classifying reference questions was found satisfactory.

\section{History and Description}

The information desk at the University of Illinois Library was first established in September 1937 as an extension service of the reference department. Its purposes were to orient students by serving as a clearing house of information about the library and to help readers in using the card catalog.

The desk is located near the public card catalog on the second floor of the library building, approximately ninety feet from the reference desk and thirty feet from the loan desk. It is placed in such a position that the assistant on duty can observe most of the persons working at the dictionary catalog and the public shelflist and it is in the direct line of traffic from the corridor to the loan desk. A sign reading "INFORMATION" occupies a prominent position on the desk during hours of attendance.

After some experimentation in the matter of hours (partially based on the findings of this study) a schedule of thirty-six and one-half hours per week is now in force. Hours of attendance at the present time are: 9- I I A.M. and 2-4:30 P.M., Monday through Friday; 7-9:30 P.M., Monday through Thursday; 9-I I A.M. and 2-4 P.M. on Saturday. During hours when the desk is not attended, it bears a sign reading "INFORMATION: Ask at Reference Desk," with an arrow which points toward the reference room.

Attendants at the desk have been members of the regular full-time staff of the reference department. Two of the younger reference assistants carry the bulk of the information desk schedule, each working approximately seventeen hours a week at the information desk and twenty-two hours in the reference department. All attendants have been qualified librarians with a bachelor's degree in library science; in addition, they have either received or have been working toward their master's degree. Several of them have had experience in cataloging, a background which has been of great value in interpreting the card catalog to students.

In order to fill some of its diverse requests, the information desk is equipped with various printed aids. Most useful of these is the Library Handbook for Undergraduate Students, which is distributed free and is also used in answering questions. Other much-used materials include: "College and Departmental Libraries and Reading Rooms in the University of Illinois Library," a mimeographed pamphlet giving locations, hours, circulation rules, etc., for all points of public service in the library system; the unabridged edition of Dewey; Library of Congress Subject Headings; a sample copy of the Readers' Guide; University of Illinois catalogs, time tables, and directories; reading lists for certain courses; a list of locations of current class reserves; a list of current periodicals kept in the reference room. Maps of the campus, mimeographed copies of filing rules, of interlibrary loan regulations, and of "Points of Interest" (a guide to the library buildings) are distributed upon occasion. A file of miscellaneous information, notes of suggestions for the catalog department, a notebook for memoranda which need to be passed on from one attendant to another, and supplies of various kinds complete the equipment of the desk.

A complete record of all questions asked has been kept since the beginning. Statis- 
tics of questions have also been tabulated. From a total of 7038 questions recorded in the school year 1937-38 the number has increased to 9754 questions in the school year 1942-43, in spite of a considerable decrease in school enrolment during the latter year.

Although primarily intended to serve undergraduate students, the desk is used also by graduate students, faculty, members of the research, administrative, and library staffs, and visitors. In recent years servicemen from nearby Chanute Field or from the Army and Navy schools on the campus have made frequent inquiries at the desk.

In carrying out its activities as a clearing house of information about the library, the desk has been of service not only to students but also to the various departments of the library. It has acted as an intermediary between students and service departments, processing departments, and library administrators.

The relationship between the information desk and public service departments is reciprocal. Loan and reference desks refer all catalog questions to the information desk attendant during hours when she is on duty. On the other hand, the attendant is able to introduce many students to the services of those departments. The same cooperation exists between the desk and departmental libraries.

Personal inquiries or telephone calls to the acquisition, catalog, and binding departments procure for patrons ordinarily inaccessible information regarding books in process or on order. At the same time suggestions based on students' needs are made to the acquisition and catalog departments, both as to the ordering of desirable titles and as to the correction of inconsistencies in the card catalog.
As a sort of "liaison officer" between students and the library administration, the information desk attendant interprets library rules and regulations to students and acts as a "listening post" for grievances regarding library practices which may need investigation.

\section{PLAN OF THE LIBRARY}

SECOND FLOOR

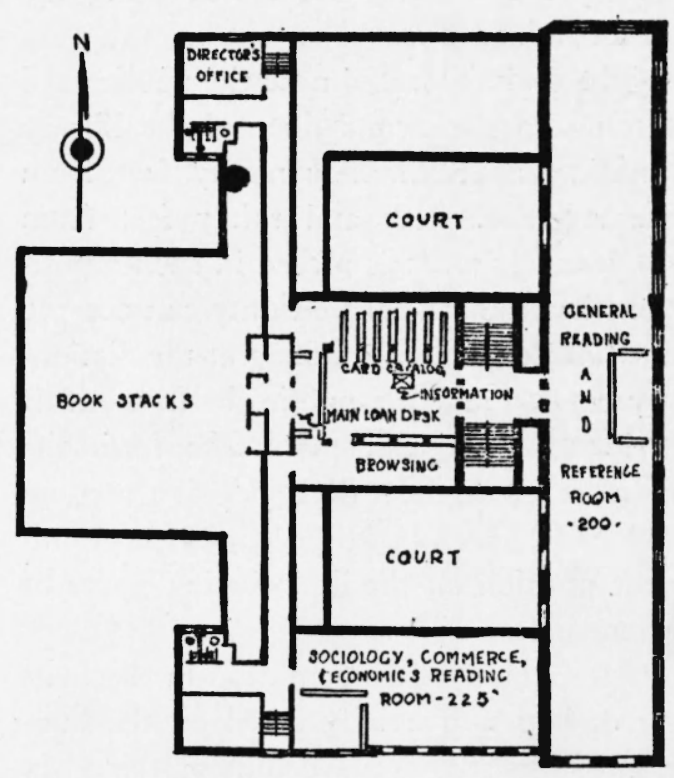

UNIVERSITY OF ILLINOIS LIBRARY INFORMATION DESK

\section{Classification of Questions}

Questions recorded at the information desk fall quite naturally into four main groups, designated as follows:

G General information questions

C Card catalog and classification questions, excluding requests for material on subjects

S Subject questions

U Unclassified questions

The first three groups are divided into primary divisions (each designated by a 


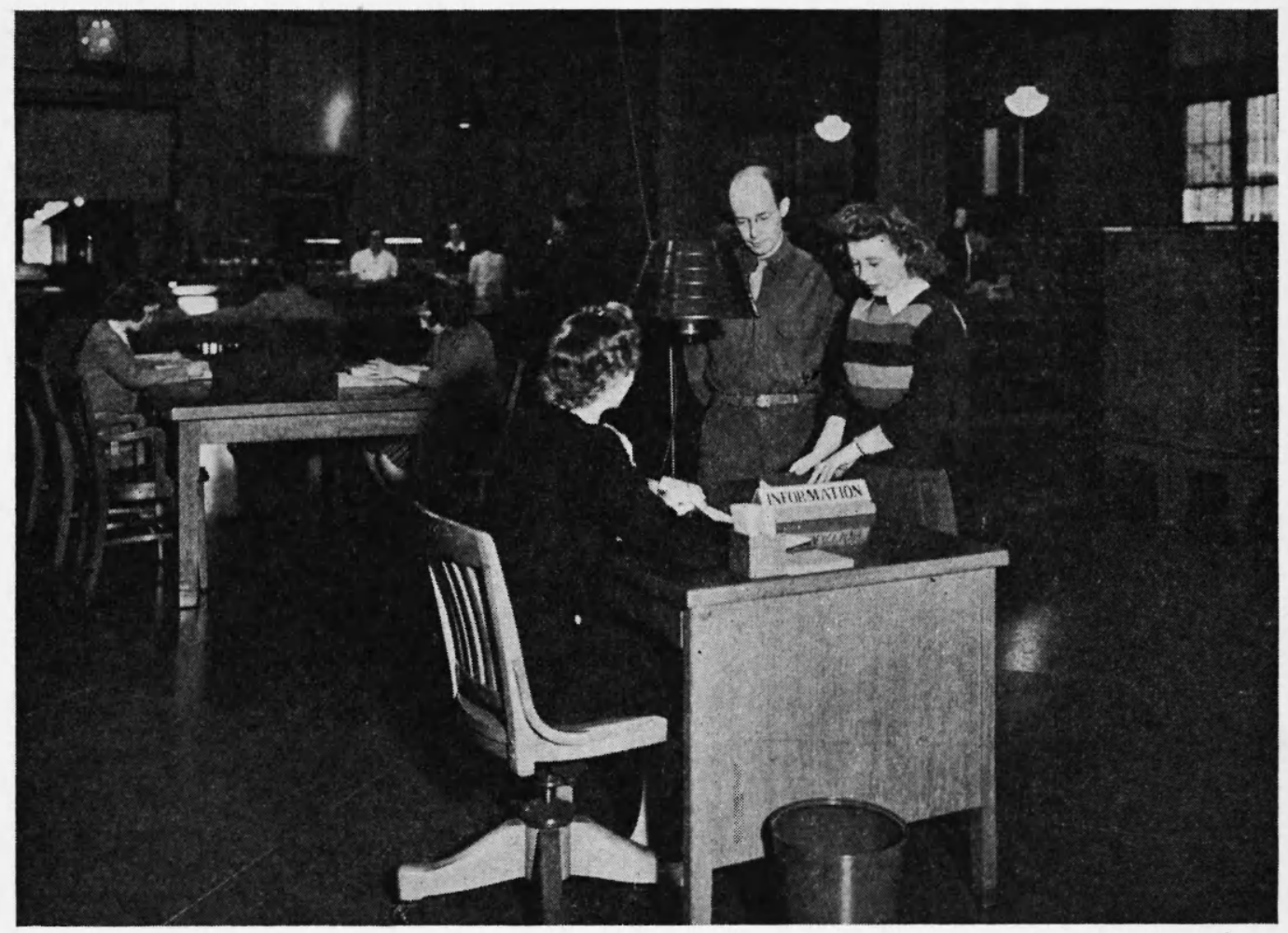

INFORMATION DESK AT THE UNIVERSITY OF ILlinoIS LibRaRy

The librarian who is dispensing the information is Ruth M. Erlandson, the writer of the accompanying article.

double letter classification) which indicate the content of the major groups. These primary divisions are briefly described below :

\section{Group $G$ General information questions}

GA General locations

GB Locations of library materials (answered without reference to the card cata$\log )$. These are requests which any librarian with experience at the desk could answer immediately.

GC General library and campus information

GD Procedures for obtaining library materials, when titles are not given and procedure only is wanted

GE Circulation rules for all public service departments
GF Questions looked up in processing departments

GG General knowledge questions, such as spelling and the meaning of common abbreviations

\section{Group $C$ Card catalog and classification questions}

CA Content and arrangement of the card catalog

CB Requests for specific library materials (answered by use of the card catalog). This includes requests for books by personal authors, government publications, nongovernment materials under corporate entries, periodicals, series, and pamphlets. Often the information given by the questioner is incomplete or incorrect.

CC Technical details of the typical unit card. Special problems here are editions and 
translations, collation difficulties, and interpretation of the location of copies.

CD Special cards and card files (not shelflist), including cross-reference cards and substitute cards

CE Filing rules

CF Library science questions (from students in the undergraduate course on library use). These are classified here because the questions such students ask at the information desk are almost entirely concerned with entries and filing in the card catalog, though the exact questions asked are not usually recorded at the desk.

CG Classification system

$\mathrm{CH}$ Use of the shelflist

CI Subject headings as such

\section{Group S Subject questions}

SA Subject questions involving use of the card catalog plus reference to materials in other departments of the library. In helping the student find subject materials through the card catalog, the desk attendant makes a practice of explaining how the items of information on a catalog card can help in evaluating the usefulness of a book for some particular purpose. The need for reading the complete title is stressed, as well as the importance of noting the date of publication, the number of pages, and notes referring to bibliographies in the book represented. Reference is always made to periodical indexes and special subject bibliographies which may be of additional help.

SB Subject questions for which materials in the reference department are recommended immediately

SC Subject questions referred directly to departments other than reference

\section{Group U Unclassified questions}

Questions whose content was not noted in the original records

\section{Summary and Conclusions}

Results of a statistical analysis of all questions recorded during the first three years of information desk service and results of the intensive subject analysis of a carefully selected sample lead to certain definite conclusions. These are discussed below in terms of the four questions set forth as objectives of this study.

\section{Character of Information Requested}

The classification scheme given above indicates the variety of requests which come to the information desk. Questions may be divided into three main classes: general information questions, questions on technical details of the card catalog and on the classification system used in the library, and requests for material on many different subjects. To these three groups is added in this study a small group of unclassified questions, so called because their content was not known and they could therefore not be placed in any of the other three groups. Within the three main classes are many divisions and subdivisions which indicate the content of each class.

A statistical analysis of questions classified by the system outlined revealed certain trends in the types of information requested at different times and indicates that the desk performs certain general functions:

a. As a general rule questions in the sample rank in descending order as follows: general questions, catalog questions, subject questions. This order in rank remains the same in all parts of the year and at all times of the day, though the percentages vary somewhat. Consequently it appears that a certain homogeneity prevails in the work of the desk throughout the year, an indication that the attendant must be constantly prepared for any and every type of question.

b. Within the three main classes there are four major divisions which constitute 55 per cent of the entire sample. These four divisions predominate in all parts of the sample and therefore may be said to form the principal portion of the duties performed at the desk. In order of rank these classes are: $\mathrm{CB}$, requests for specific library materials which require use of the card cata- 
log; GA, requests for locations of places, persons, and supplies; SA, subject questions involving use of the card catalog plus reference to materials in other departments of the library; and $G B$, requests for library materials whose location in the library can be supplied by experienced attendants without search in the card catalog.

It may be noted that these four "staples" include at least one division from each of the three main classes of questions. This fact probably indicates that the desk has achieved its original purposes of orientation in library locations and procedures, instruction of students in use of the card catalog, and direction of students' search for subject materials. Since two of these four major divisions are concerned with the location of specific library materials, it may be concluded that students come to the library to look up specific books more often than they come to search for materials on given subjects.

\section{Subdivisions}

c. Within the four major divisions listed above, certain subdivisions predominate, indicating that even minor groups in the classification should not be overlooked in listing trends.

Among requests for specific materials which require use of the card catalog, over half apply to books by personal authors.

The great majority of requests for locations of places, persons, and supplies are concerned with locations of rooms in the library building.

A study of subject questions (both those requiring use of the card catalog and those directly referred to other departments of the library) indicates that the four highest ranking subjects are: social sciences (with economics, criminology, and education predominating), useful arts (particularly medicine and business), history (especially travel and biography), and fine arts (chiefly music and recreation). The prevalence of these subjects may be considered an indication that the main library is used largely by students in the schools of liberal arts and sciences, commerce, education, physical education, and music. These are schools which do not have special libraries in their own buildings but depend on resources of the main library for study materials.

Requests for materials of well-known location include chiefly questions about the general location of reserve sections for specific courses and for specifically named books.

d. Over half the general questions in the sample were recorded during the first week of the school year. In other words, the number of general questions asked during the first week of any school year is likely to be twice as great as during any midsemester week. In contrast, catalog questions are fairly well distributed through the year, the largest number of requests in the sample occurring in the middle of the first semester. Subject questions follow the same pattern as catalog questions, though the subject questions reach a higher peak during the middle week of the first semester than do catalog questions.

e. Though general, catalog, and subject questions rank in that order at all times of the day, in the evening period the actual number of general questions decreases while the number of catalog and subject questions increases. This may be considered an indication that students are more likely to come to the library for serious study at the time of day when class schedules are least likely to interrupt continuous work.

f. The classification of questions reaffirms the statement that the desk serves the library as well as the students, by introducing students to the services of the public departments, by relieving the loan and reference departments of certain duties, by making available to patrons information from processing departments which are not open to the general public, and by interpreting to library users regulations formulated by the library's administrators.

\section{Qualifications of Desk Attendants}

From the three main groups of the classification scheme for questions, it may be concluded that the following qualifications are desirable for information desk attendants: experience in the library where the desk is located, for complete familiarity 
with procedures, rules, and locations; cataloging training and experience; thorough knowledge of the resources and services of the reference department and to some extent of other departments of the library ; and a good general background in many subjects.

Two of these qualifications indicate the need for at least one year of professional library training. A further examination of individual questions, particularly those from faculty members and graduate students, proves the additional value of advanced courses in bibliographic techniques and other studies related to the subject of books.

The personality traits desirable in an information desk attendant are those necessary for any librarian who is working directly with the public. However, the cardinal qualification in this instance might be said to be a certain "approachableness," based on a genuine liking for students and a desire to help them solve their library problems. The informality of a small desk placed in a room where absolute quiet is not demanded, as contrasted with the more restrained atmosphere of "counter service," provides an excellent opportunity for making friendly contacts for the library and creates an atmosphere in which students feel free to express themselves. For such informal service an assistant who is dignified and well informed but whose manner is not too formal or "institutional" is required.

\section{Desirable Periods of Service}

From the point of view of the number of questions recorded at the desk, the most important periods of service are the first two weeks of the school year, weeks toward the end of the first semester, and weeks in the middle of the second semester.
Monday, Tuesday, and Thursday are the busiest days.

In practically every instance the evening period of service is busier than the daytime hours. Afternoon hours are often very busy also, though usually they approach the average for the day. These findings suggest two recommendations: that the evening period of service is essential; that, if necessary to shorten the hours of service, the morning period could be dispensed with more easily than the afternoon and evening periods.

The conclusions in the preceding paragraph are based on summary figures and cannot serve as a valid means of predicting the number of questions to be expected on any one day. Variations in class assignments and in events on the general and university calendars must be considered. Furthermore, these conclusions do not take into account the fact that in a statistical analysis all questions are counted equal, in spite of considerable inequality in the time and experience required to answer various requests.

A brief survey of the amounts of time required for answering questions shows that, while most questions can be answered in a minute or less, others (particularly subject and catalog questions) require ten minutes or more for satisfactory completion. It is evident, then, that a simple count of the number of questions leads to a less accurate appraisal of the amount of work accomplished than does a consideration of the kinds of questions and the amount of time and experience needed to answer them.

The subject analysis indicates that the large number of questions during the first weeks of the school year is caused by lack of familiarity with the local library and its procedures. That same qualitative analy- 
sis shows that subject and catalog questions are more or less stable in quantity throughout the year, increasing slightly after the first weeks. Because these two latter types of questions require assistance of a more professional nature and usually require more time than do the general questions, it seems conclusive that service should not be limited to the early weeks but should be continued throughout the year.

Since the qualitative analysis shows that catalog and subject questions are more highly concentrated in the afternoon and evening hours, the conclusion that those periods of service should be retained and, if possible, increased in length (even though morning hours should have to be discontinued) is reaffirmed. In general, however, it is impossible to predict exactly which periods of the year or hours of the day may be busy or dull; too many factors beyond the control or vision of the librarian are present for such an analysis as this to be able to foretell exactly what is to be expected.

\section{Library Handbooks}

If it can be assumed that the questions asked by patrons at the information desk are representative of what students need to know about their library, the classification scheme given above and the analysis of the relative importance of various types of questions should prove a logical source of suggestions for the content of library handbooks for students.

Apparently students need to know locations, procedures, and rules of the library; they need to know the fundamental principles of catalog use; they need some orientation in search for subject materials and a description of the public service departments which can help them obtain such materials; they need to be taught the value of certain reference tools in common use.

It has been questioned whether the publication of a library handbook renders unnecessary such information service as has been described here or whether such information service renders a handbook superfluous. It may be well, therefore, to point out the particular value of each.

A library handbook, if distributed to groups outside the library, can show students who have not yet visited the library building just what facilities are to be found there. The information desk can help only those who have already come to the building.

The printed handbook gives uniform information to every student so that each one may learn the fundamentals of library use. It can serve as an aid when there is not a librarian present to give appropriate explanations. It answers questions objectively and concisely, whereas oral explanations are likely to be less carefully considered and less complete. On the other hand, the handbook cannot take into account either the differences in students' previous experience in library use or the particular details of his present problem. The information desk deals with the specific and individual problem in terms of the obvious need of the inquiring student.

At the University of Illinois Library, information desk attendants have found the Handbook useful as a tool in explaining the use of the library. It has been distributed to students who wish general information about the library in a convenient form for their own reference. It has also been used at the desk to explain, from its illustrations and its text, such matters as the proper method of filling out a call slip, the parts of the catalog card, or the location of rooms in the library building. (Continued on page $6_{I}$ ) 
record. Evidence of the success of an exhibit planned to teach a lesson or to tell a story is far less tangible and can hardly be measured in terms as concrete as gifts or statistics. If, however, in the planning, assembling, and arranging of the exhibit, thoughtful consideration is given the techniques of exhibition which are soundly based upon principles of applied psychology, the success of the exhibit will tend to be ensured.

The purpose of an exhibit once defined and justified will generally indicate the logical group toward which the exhibit should be directed. A college library exhibit prepared to attract donations will in all probability be directed toward prosperous alumni and influential Friends of the Library. An exhibit planned to enrich the teaching program of a certain faculty member will be aimed at students enrolled in his classes. Purpose and audience are inseparable in the preparation of an exhibit, and other factors to be considered will hinge largely upon these two. They govern the theme or central idea of the exhibit; they influence selection and arrangement of materials and the location of the exhibit itself; they determine the length of exhibition period and the type and amount of publicity the exhibit deserves. Purpose and audience serve as the framework around which an exhibit is built. How well the exhibit is built depends largely upon the judgment and skill with which the exhibitor selects and arranges his materials, relating them through appropriate written interpretations into an attractive whole which clearly expresses the theme of the exhibit.

The ideal college library exhibitor would seem to combine with the characteristics of librarian those of psychologist and artist with a proper balance among the three. He never allows his enthusiasm for drawing attention to the exhibit to overshadow its real purpose and divert attention elsewhere; he never permits his zeal for creating a masterpiece of artistry to make his primary purpose a secondary one; and he never lets his background as librarian blind him to the fact that, though books in themselves may be infinitely delightful to him, an exhibit of them can be made more attractive and alive to others if, in its planning and arrangement, a due regard is given the principles of applied psychology and artistic design.

\section{An Analysis of the Work of the Information Desk at the University of Illinois Library}

\section{(Continued from page 43)}

At the same time the attendant supplements printed rules with oral explanations applicable to the particular problem.

All things considered, it is evident that no printed handbook can be expected to take the place of an information service conveniently located and attended by a trained librarian who can not only explain general rules but also give specific help with the problem at hand. An information desk provides personal instruction in use of the library at the point where the student is most likely to encounter a need for such instruction. 